\title{
The design evaluation and reuse recommendation for Japanese naval facilities located at Fongshan Wireless Telecommunication Station in Taiwan
}

\author{
C.-K. $\mathrm{Ku}$ \\ Department of Architecture and Interior Design, Cheng-Shiu University, \\ Taiwan
}

\begin{abstract}
Fongshan Wireless Telecommunication Station (FongshanWTS) used to be listed as one of the three biggest wireless telecommunication stations in Japan. The buildings in the FongshanWTS offer a great deal of information related to the histories of construction technology, military installation and telecommunication equipment for precious historical assets in Taiwan. According to the official record, FongshanWTS was constructed from 1917-1919, and the design technology was originated from Germany. The reason why and how it was constructed in Taiwan, and also the evaluation of design technology and reuse recommendation are discussed in this paper. Since the history of FongshanWTS involves four countries, e.g. Taiwan, Japan, China and Germany, it is the purpose of this paper to get correlated information from this international conference, especially from those countries in Europe. Keywords: wireless telecommunication station, telecommunication, reuse.
\end{abstract}

\section{Introduction}

There are many Japanese vestiges of military facilities in the southern part of Taiwan, particularly at Kaohsiung. Some of these facilities have been demolished not only because of the reconstruction project for the military housing community, but also because of the disarmament plan in Taiwan. The land area used for military affairs is actually considerably large in Kaohsiung. The popularization of martial culture has led to the desire to witness the history 
of military affairs in this region. It has been more than 60 years since the end of WWII. The conservation of military facilities needs to be taken into consideration.

\section{Historical background}

The historical background can be traced from the end of the 19th century. After winning the Sino-Japanese war of 1895, it was approved that the Japanese had developed the navy force successfully in the past. Consequently, this made Japan expand the navy force more confidently and more actively. The Japanese parliament originally had widespread comment about too great an expenditure on the navy; however, the expansion action of the navy was accepted at this time [1]. In addition, at the beginning of the 20th century, Japan became the only country in Asia that stood side by side with American-European big powers by defeating Russian. From the Shimonoseki Treaty in 1895 to the Japan-Russia war in 1905, the Japanese navy had been developed very quickly within this decade. Taiwan was incorporated into the domain of Japan in this military expansion and became the first colony of Japan.

The key point that allowed the Japanese navy to conduct a military operation successfully at that time depended on the newly developed weapon in the battlefield, the wireless telecommunication machine (which was developed at the beginning of the 20th century). Therefore, in 1915, the first wireless telecommunication station on a large scale was completed at Funabasi in Japan. Then the second one, Fongshan located in Taiwan, was chosen as the second wireless telecommunication station and finished in 1919. The last one was completed at Hario in 1922 [2]. With three large-scale wireless telecommunication stations finished within nine years, the geographical distribution should be considered as a whole. Namely, Funabasi was near the capital Tokyo, it was the heartland of the political center in Japan; Hario in Sasebo is the location of the naval port in the west-coastal end of Japan, and can monitor Korea or even China; Fongshan was near the naval base at Kaohsiung which is in the southern territorial end of Japan, and from here it was easy to get in touch with the archipelago of the south Pacific Ocean.

After WWII, a lot of people and military forces from Mainland China moved to Taiwan, especially after 1949. At that time, besides the wireless telecommunication function, FongshanWTS was also used as a prison for political offenders. Some of them were taken as the suspects of Chinese Communist agents and died there [3]. Therefore, FongshanWTS is not only the technical place for wireless telecommunication, but also the memorial place for those people who died there for political reasons.

Among these three wireless telecommunication stations, the Funabasi Wireless Telecommunication Station (FunabasiWTS) was originally constructed by Germany and no longer exists now. Hario Wireless Telecommunication Station has nothing left now but three wireless towers made of reinforced concrete. It seems more important for FongshanWTS to keep the related cultural assets. The preservation and reuse of FongshanWTS are under consideration at this moment in time. 


\section{Landscape of surrounding environment}

\subsection{Funabasi Wireless Telecommunication Station in Japan}

Funabasi Wireless Telecommunication Station was located near Tokyo. The disposition of FunabasiWTS is shown in Figure 1. The diameter of the outer circle is $800 \mathrm{~m}$. The major steel tower with a height of $200 \mathrm{~m}$ was situated at the center of the circle. The wireless telecommunication room was located beside the major tower. There were also 18 secondary steel towers around the outer circle with equal distance between each other [4].

FunabasiWTS was constructed by technicians from Germany. The construction began in October 1913 until the beginning of WWI. The related design drawings were burned before the technicians hastily returned to Germany in August 1914. At that time, only the foundations of the major steel tower were finished. The big wireless telecommunication machines were not yet assembled. However, the remaining parts of FunabasiWTS were finally completed by Japanese technicians on their own in April 1915 [5]. Nevertheless, it was demolished in 1971.

It could be more interesting if similar wireless telecommunication stations can be found in Germany or other countries in Europe. The correlations of wireless telecommunication stations among Taiwan, Japan and European countries can be connected.

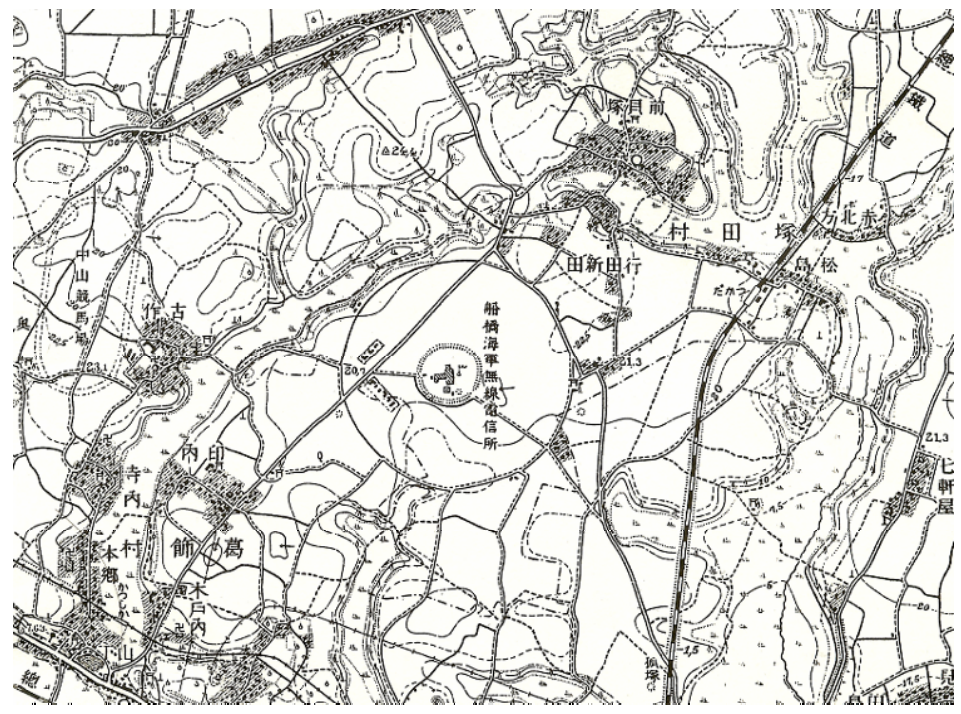

Figure 1: $\quad$ The disposition of FunabasiWTS.

\subsection{Fongshan Wireless Telecommunication Station in Taiwan}

The surrounding configuration for FongshanWTS is illustrated in Figure 2. Farmland originally surrounded the FongshanWTS when it was constructed. 
However, only the eastern side is farmland now. The remaining foundations for fixing $60 \mathrm{~m}$ high antennas are kept in this area. The oncoming urban planning for this area is residential district. How to preserve these foundations becomes an intricate issue now.

There is a primary school on the south side. The western part has several buildings with different functions, e.g. traditional market, military dependants' remodelling residences, veterans' service center, military welfare supply center, junior high school, etc. The military dependants' remodelling residences will be constructed this summer. The military dependants' housing located in the northern part was constructed 43 years ago and will be demolished after the remodelling residences are finished.

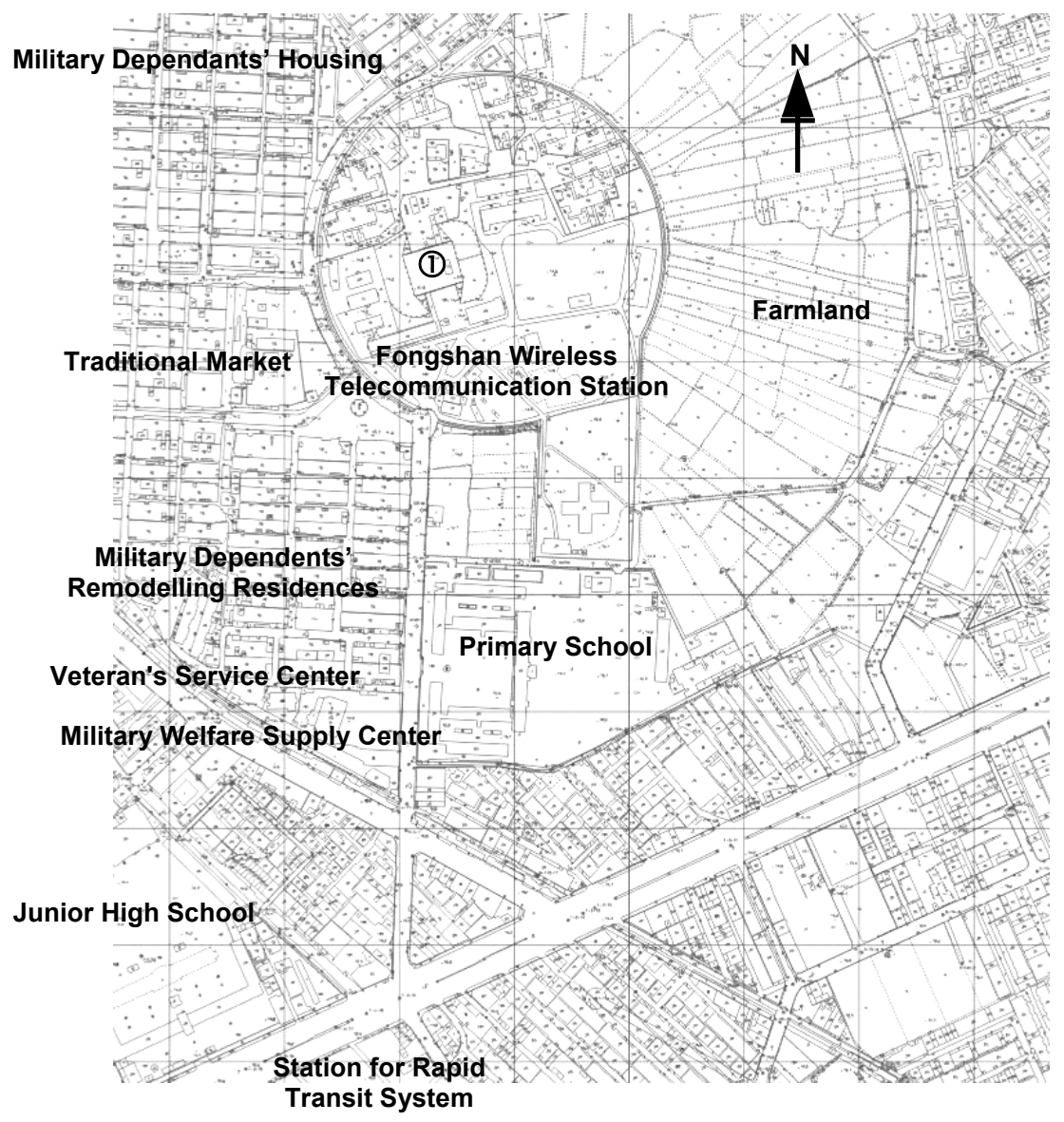

Figure 2: The surrounding configuration for FongshanWTS. 
The construction of FongshanWTS began in the summer of 1917, and finished in May 1919. The aerial view of FongshanWTS and the related foundations for fixing antennas are displayed in Figure 3. The design conception was the same as that for FunabasiWTS. There was also a steel tower with a height of $200 \mathrm{~m}$ situated at the center of the circle, and 18 secondary steel towers, where were the same as FunabasiWTS, with a height of $60 \mathrm{~m}$, surrounded the outer circle. The small circles, marked as $\mathrm{A}, \mathrm{B}$, and $\mathrm{C}$ circles as shown in Figure 3, were the foundations to fix the antennas. The diameter of circle $\mathrm{A}$ is $800 \mathrm{~m}$, while the diameters of circles $\mathrm{B}$ and $\mathrm{C}$ are $680 \mathrm{~m}$ and $260 \mathrm{~m}$ respectively as shown in Figure 4.

There were 36 foundations situated in circle A, but only six remain, they are marked as A5, A6, A7, A11, A14 and A19 in Figure 3. The A11 foundation is displayed in Figure 5. There were 18 foundations in circle B, only B2 to B7 are left now. All these foundations in circles A and B are the same size, namely length $400 \mathrm{~cm} \times$ width $250 \mathrm{~cm} \times$ height $112 \mathrm{~cm}$. The biggest foundations for fixing antenna were $\mathrm{C} 1$ to $\mathrm{C} 3$ with length $10 \mathrm{~m} \times$ width $7 \mathrm{~m} \times$ height $2.6 \mathrm{~m}$. The $\mathrm{C} 2$ foundation is shown in Figure 6.

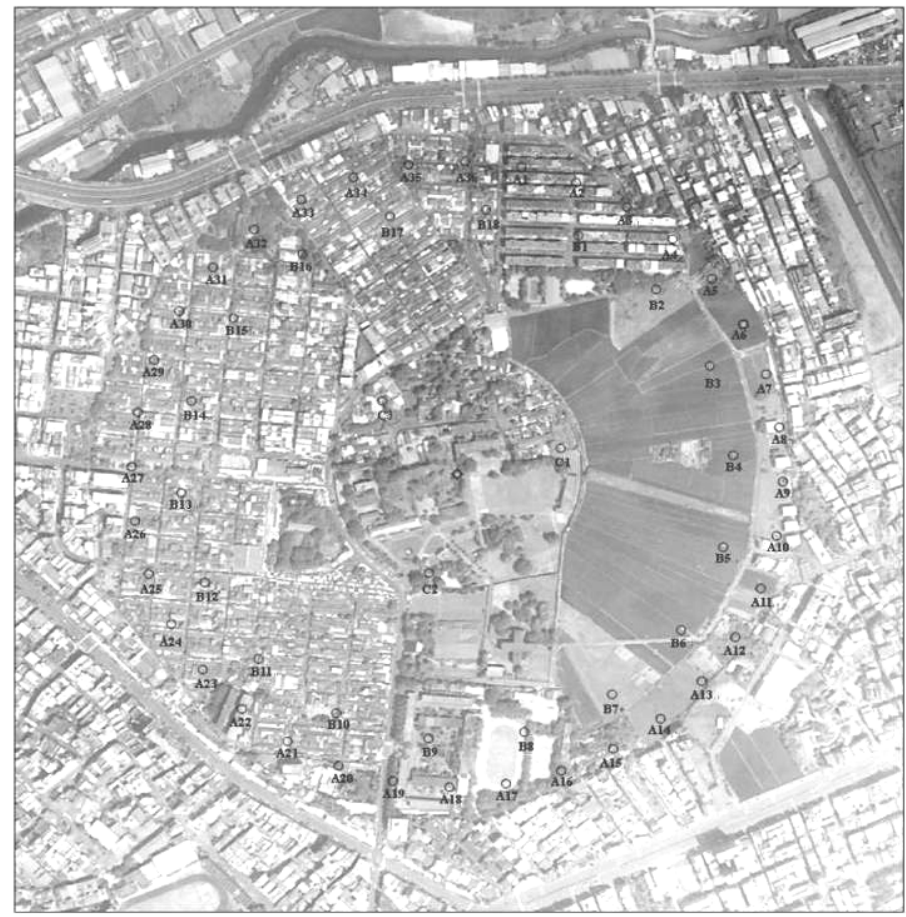

Figure 3: The aerial view of former FongshanWTS with the small circles marking the locations of foundations. 


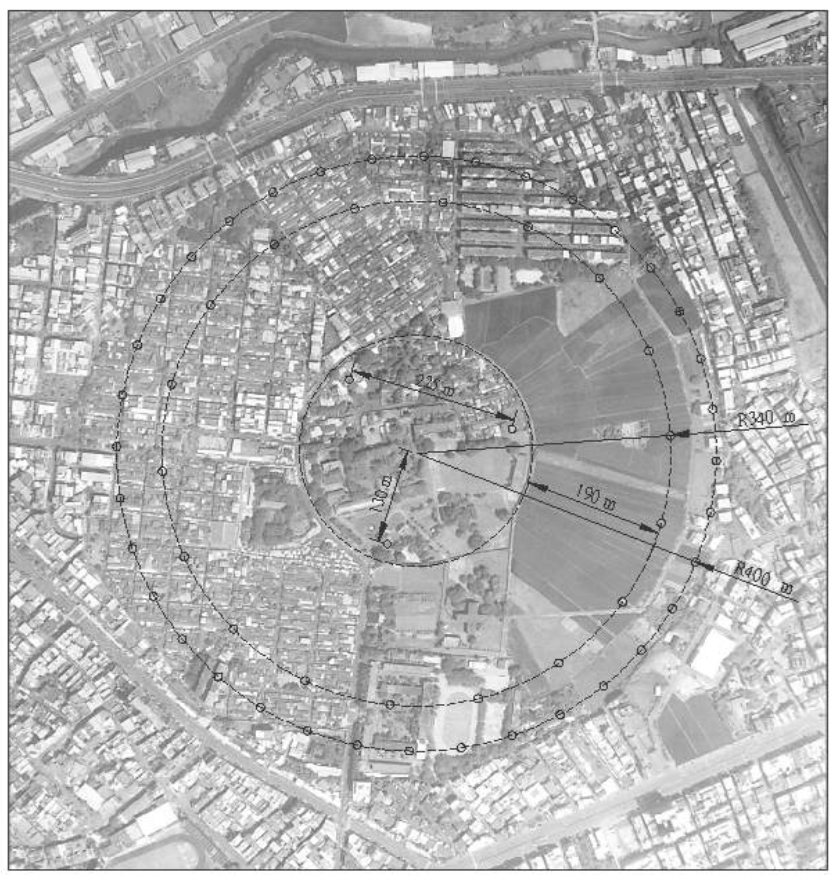

Figure 4: The black lines mark the diameters of the foundations for fixing antennas.

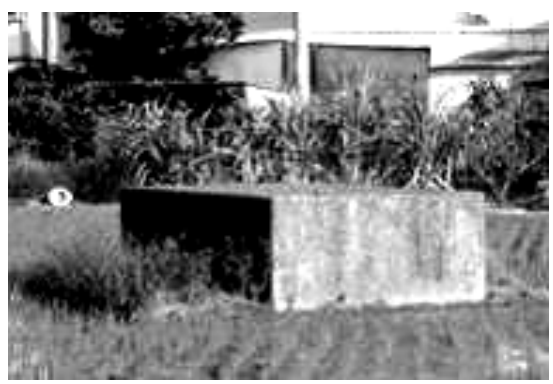

Figure 5: The A11 foundation for fixing antenna.

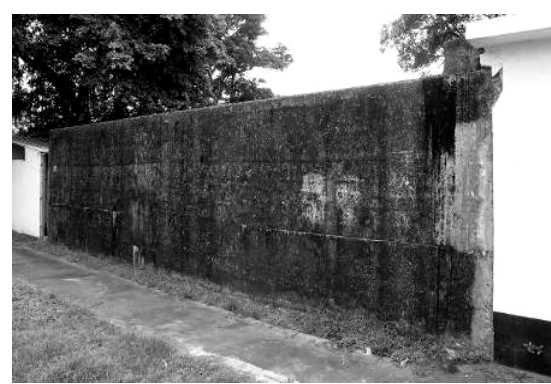

Figure 6: The C2 foundation for fixing antenna.

\section{The design configuration of telecommunication room}

There are 15 historical buildings in FongshanWTS, they are the telecommunication room, office buildings, water tower, ammunition installation, infirmary, dormitories for officers and soldiers, etc. The representative building in this station is the telecommunication room marked as number (1) in Figure 2. The plan is approximately rectangular with slopes stepping from both sides and 
covered with soil. The roof is covered with quite deep soil in order to prevent bombing from the air. The height of the telecommunication room is $12.3 \mathrm{~m}$. There are 13 blast-resistant windows and six blast-resistant doors as illustrated in Figure 7. The blast-resistant doors and windows are made from reinforced concrete with a steel frame attached to the outside. The whole structure is made from reinforced concrete, especially in the north-south direction, while the partition walls in the east-west direction are made from bricks.

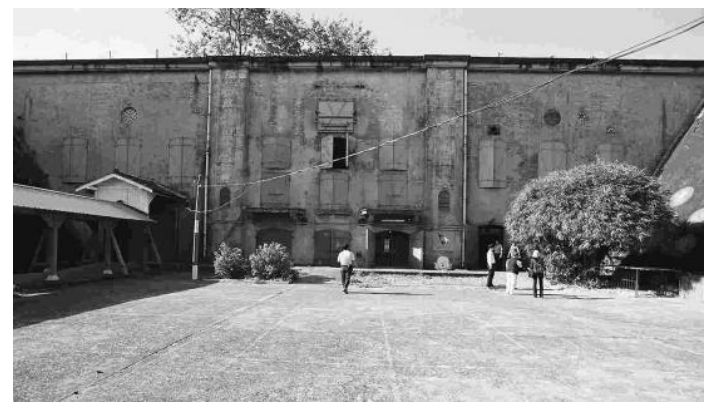

Figure 7: South elevation of the telecommunication room.

There are three long tube shaped spaces inside the telecommunication room as shown in Figure 8. The circles on top of the right hand side and left hand side arches are installations of electric lines for the power supply. The circle on the central top of the arch is a big fan for ventilation. The right hand tube has two stories. The second floor is a wooden structure with cryptomeria girders. The timbers were transported from Japan. The central tube also has two stories, but the second floor is made of reinforced concrete and fire-resistant bricks. The left hand side tube is a machinery room with a travelling hoist on the top of the columns.

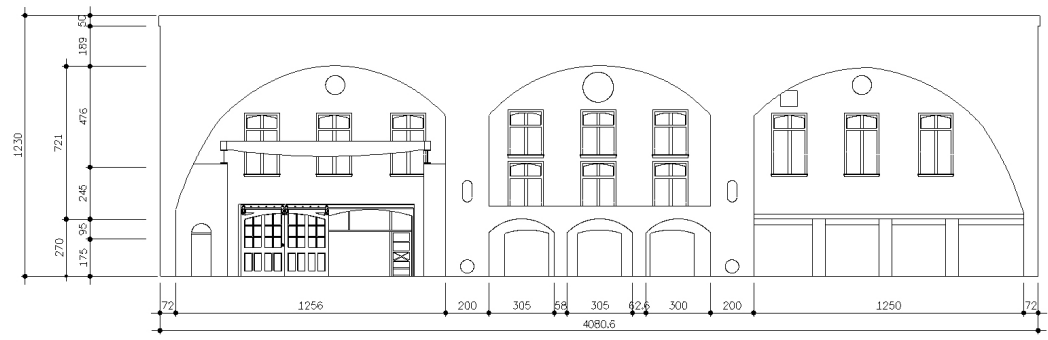

Figure 8: Cross-section of the telecommunication room.

\section{Reuse significances}

The reuse significances for FongshanWTS are listed as follows [6]: 


\section{Continuity of native culture}

The FongshanWTS is like the long lane of history, from a Japanese telecommunication station to a Taiwanese anti-communism base. Every scene, every thing, even a copy of the precise loyal sentiment, aspiration and spirit that were dedicated to the service of the country resulted in some touching stories and anecdotes that should be preserved.

\section{Extension of education on martial culture}

There are several military bases in Fongshan that are known around the whole country. Before 1945, the Japanese managed battlefields in southern Taiwan. The Ministry of National Defence in Taiwan still continues to use the peripheral military installations in Fongshan. The land area used for military affairs is actually considerably large. The popularization of martial culture has led to the desire to witness the history of military affairs.

3. Manifestation of historical framework, activation of historical district

The government of the Republic of China moved from the mainland to Taiwan in 1950. In order to prepare for counterattack, the housing for military dependants was established near the military camps. The landscape of the military housing community and agricultural society nearby showed simple and honest humanity. Based on social values and cultural changes, it is the historical mission to activate the district if combining FongshanWTS with the traditional market, military dependents' remodelling residences, military welfare supply center, veterans' service center, junior high school, primary school, shopping street and the station for rapid transit system, and so on.

\section{Recollection of local emotion and utilization of spare space}

The existence of the FongshanWTS is in the memory of the military housing community and local neighborhood. It is all closely related to the education network in this area from primary school to junior high school, even to college. As military dependants' housing is reconstructed, an extensive population will move into this area. It can offer enough space for activities and recreation usages.

\section{Reuse recommendations}

The FongshanWTS was constructed 90 years ago. Most buildings in this station should be repaired. The short-term and long-term objectives of reusing this station are listed below [6].

\subsection{Short-term objectives}

\section{Planning and design}

The damage level of the buildings should be assessed and the planning of work for space, safety devices, maintenance and repair technology should be undertaken. 


\section{Applying trusteeship}

The related documents are assembled, including trusteeship planning, authentications of official departments and the institutional framework of trusteeship. FongshanWTS is now managed by the organization, "Cultural Developmental Confraternity for Kaohsiung Military Housing Community".

\section{Introducing civic organizations}

There are some organizations in the nearby area. Relevant organizations can be introduced to adopt this district, and the co-management organizations can be taken as the basic administrative units in the future.

\section{Volunteer training}

Through volunteer training, the culture assets can be realized, the environment can be known, the mission can be understood, and the area of responsibility can be adopted.

\section{Space opening}

The space will be opened for residents' recreation activities. The interior spaces of the buildings can be taken as the classroom for local organizations and folks. The surrounding environment can be realized through opening the space. The function of managing the space; therefore, can be fulfilled by users' maintenance.

\subsection{Long-term objectives}

1. Establishment of a cultural recreation center

After successively finishing the construction and repair work of the FongWTS in the relevant stages in accordance with the plan, the goal of constructing a cultural recreation center can be implemented. This district can be moulded as the space for local recreation, performing art and historical cultural continuity.

The name "Martial History Station for Fongshan Wireless Telecommunication" was proposed for the former FongshanWTS this year. It is expected that this historical station will be kept and utilized properly, enriching the cultivation of the community, allowing the preservation of cultural assets and the improvement of local economy to bring out the best in each other.

\section{Introducing business activities}

Many public places in Fongshan are managed through conducting commercial activities at present, and these activities have developed the local characteristics of the city. The traditional delicate food in the military dependants' community was originated from northern China and having its special flavour. In addition, coffee and table delicacies are introduced through proper commercial activities, thus the local economy can be activated. The income from commercial activities can be taken as the funds for managing and safeguarding this station. 
3. Experiencing environmental adventure

A sustainable base for local organizations can be provided, and the multifunctional study space and its high additional value can be offered; for instance, as an environmental education base for nearby schools, social activities for local organizations and construction practice place, etc.

\section{Touring local characteristics}

After finishing the relevant software and hardware improvements in this district in the future, it cannot only be used as the living space for residents, but the local distinguishing features can also be established. In addition, local sightseeing through performing arts and festival celebration activities can be improved, and so on.

\section{Conclusion}

FongshanWTS was one of the three biggest Japanese wireless telecommunication stations before WWII. It represents the developmental history of wireless telecommunication, having an historical value that cannot be replaced. In addition, after the navy of the Republic of China took over this station, it was divided into military dependent's housing and a training base for offenders in the navy. It has its own special historical background that has many stories.

It is more interesting if similar design schemes of wireless telecommunication stations can be found in Germany or other countries in Europe. The international correlations of such wireless telecommunication stations among Taiwan, Japan and European countries can be achieved.

\section{References}

[1] The conservation of navy history foundation, Japanese navy history, volume I, Tokyo. The first regulation publish corporation, p.245, 1995.

[2] The conservation of navy history foundation, Japanese navy history, volume V, Tokyo. The first regulation publish corporation, p.464, 1995.

[3] Ku, C.K., Chen, C.C. \& Han, S.S., The Investigation and Repair Report for Former Telecommunication Base of Japanese Navy at Kaohsiung County (Ming-Der Navy Training Base), Kaohsiung County Government, pp.2-8 2$10,2006$.

[4] Committee for Electric Wave Supervision, The History of Japanese Wireless Telecommunication, volume X, p.440 441, 1951.

[5] Committee for Electric Wave Supervision, The History of Japanese Wireless Telecommunication, volume X, p.49, 1951.

[6] Ku, C.K., The history and reuse of Fongshan wireless telecommunication station. Proceedings of International Conference on the Installation, Design and Reuse of Japanese Military Facilities in Taiwan, National Center for Research and Preservation of Cultural Properties, Taiwan, pp.4-15 419, 2006. 